\title{
PENGARUH PEMBERIAN TERAPI FISIK BRANDT DAROFF TERHADAP VERTIGO DI RUANG UGD RSUD DR. R SOEDARSONO PASURUAN
}

\author{
Nike Chusnul Dwi Indah Triyanti, Tri Nataliswati, Supono \\ Poltekkes Kemenkes Malang, Prodi Keperawatan Lawang, Jl. Ahmad Yani, Sumberporong, Lawang \\ Email: nikechusnul@gmail.com

\section{The Effect of Physical Therapy Brandt Daroff on Vertigo at UGD RSUD Dr. R Soedarsono Pasuruan}

\begin{abstract}
Vertigo is phenomenon that is sometimes often found in society. The purpose of this study was to determine the effect of physical therapy brandt daroff on vertigo at UGD RSUD Dr. $R$ Soedarsono Pasuruan. The research design used was equal experiment the number of samples obtained by 30 respondents, sampling using method non probability sampling, instrument used is vertigo symptom scale-short form (VSS-SF) to measures vertigo score, data analysis using Wilxocon Sign Ranking Test with a significant level $\alpha=0,05$. The results of research indicate the influence of physical therapy Brandt Daroff on vertigo ( $p$ value $=0,000<0,05$ ). The recommendations of this study are patiens who experience vertigo in order to get physical therapy brandt daroff action because it can reduse vertigo.
\end{abstract}

Keywords: physical therapy brandt daroff, vertigo

\begin{abstract}
Abstrak: Vertigo merupakan suatu fenomena yang terkadang sering ditemui di masyarakat. Tujuan pada penelitian ini adalah untuk mengetahui pengaruh pemberian terapi fisik Brandt Daroff terhadap vertigo di UGD RSUD Dr. R Soedarsono Pasuruan. Desain penelitian yang digunakan adalah Quasi Eksperimen jumlah sampel yang di peroleh sebanyak 30 responden, pengambilan sampel menggunakan metode Non Probability Sampling, instrument yang digunakan adalah vertigo Symptom Scale-Short Form (VSS-SF) untuk mengukur skor vertigo, analisa data menggunakan uji Wilxocon Sign Ranking Test dengan taraf signifikan $\alpha=0,05$. Hasil penelitian menunjukkan adanya pengaruh pemberian terapi fisik brandt daroff terhadap vertigo ( $p$ value $=0,000<0,05)$. Rekomendasi hasil penelitian ini adalah pasien yang mengalami vertigo agar mendapatkan tindakan terapi fisik Brandt Daroff karena dapat mengurangi vertigo.
\end{abstract}

Kata Kunci: terapi fisik brandt daroff, vertigo

\section{PENDAHULUAN}

Vertigo merupakan suatu fenomena yang terkadang sering ditemui di masyarakat. Vertigo adalah suatu gejala atau perasaan dimana seseorang atau benda di sekitarnya seolah-olah sedang bergerak atau berputar, yang biasanya disertai dengan mual dan kehilangan keseimbangan. Jika sensasi atau ilusi berputar yang dirasakan adalah diri sendiri, hal tersebut merupakan vertigo subjektif. Sebaliknya, jika yang berputar adalah lingkungan sekitarnya, maka itu disebut vertigo objektif (Rustinah, 2008; Mudzakir, et al., 2009). Seseorang yang mengalami vertigo akan mempersepsikan suatu gerakan yang abnormal atau suatu ilusi berputar. Vertigo dapat berlangsung sementara maupun berjam-jam namun juga bisa berlangsung ketika seseorang tersebut dalam kondisi tidak bergerak sama sekali (Mudzakir, et al., 2009).

Vertigo sendiri dapat disebabkan oleh kelainan di dalam telinga tengah, pada saraf yang menghubungkan telinga dengan otak, dan kelainan penglihatan karena adanya perubahan tekanan darah yang terjadi secara tiba-tiba. Prevalensi vertigo di Amerika sebesar $85 \%$ yang disebabkan oleh gangguan sistem vestibular akibat adanya perubahan posisi atau gerakan kepala (Marchiori, et al., 2010).

Penyakit vertigo ini merupakan keluhan yang sering dijumpai dalam praktek yang digambarkan sebagai rasa berputar, pening, tak stabil (giddiness, unsteadiness) atau pusing (dizziness). 
Prevalensi vertigo di Jerman, berusia 18 tahun hingga 79 tahun adalah 30\%, 24\% diasumsikan karena kelainan vestibuler. Penelitian di Prancis menemukan 12 bulan setelahnya prevalensi vertigo 48\% (Grill et al., 2013; Bissdorf, 2013). Prevalensi di Amerika, disfungsi vestibular sekitar $35 \%$ populasi dengan umur 40 tahun ke atas (Grill et al., 2013). Pasien yang mengalami vertigo vestibular, 75\% mendapatkan gangguan vertigo perifer dan $25 \%$ mengalami vertigo sentral (Chaker et al., 2012).

Di Indonesia angka kejadian vertigo juga sangat tinggi, pada tahun 2010 dari usia 40 sampai 50 tahun sekitar 50\% yang merupakan keluhan nomor tiga paling sering dikeluhkan oleh penderita yang datang ke rumah sakit, setelah nyeri kepala, dan stroke (Sumarilyah, 2010; Widiantoro, 2010). Umumnya vertigo ditemukan sebesar $15 \%$ dari keseluruhan populasi dan hanya $4-7 \%$ yang diperiksakan ke dokter (Sumarilyah, 2010).

Dari data studi pendahuluan yang sudah diambil di UGD RSUD dr R.Soedarsono kota Pasuruan jumlah pasien vertigo tahun 2016, bulan Juni 32 orang, bulan Juli 37 orang, Agustus 35 orang, bulan September 41 orang, bulan Oktober 35 orang, dan bulan November 40 orang. Kejadian vertigo di RSUD dr R Soedarsono kota Pasuruandari bulan Juni-November 2016 sejumlah 220 kasus.

Vertigo adalah adanya sensasi gerakan atau rasa gerak dari tubuh seperti rotasi (memutar) tanpa sensasi peputaran yang sebenarnya, dapat sekelilingnya terasa berputar atau badan yang berputar. Keluhan yang paling sering dijumpai dalam praktek. Vertigo berasal dari bahasa latin "vertere" yaitu memutar. Vertigo termasuk ke dalam gangguan keseimbangan yang dinyatakan sebagai pusing, pening, sempoyongan, rasa seperti melayang atau dunia seperti berjungkir balik. Vertigo paling sering ditemukan adalah Benign Paroxysmal Positional Vertigo (BPPV). Menurut penelitian pasien yang datang dengan keluhan pusing berputar/vertigo, sebanyak 20\% memiliki BPPV, walaupun penyakit ini sering disertai penyakit lainnya (Wreksoatmojo BR., 2010).

Salah satu faktor pasien yang mengalami vertigo atau kekambuhan gejalanya biasa disebabkan oleh kelelahan, lesu, gangguan pada organ gastrointestinal, nyeri otot, hipertensi (tekanan darah tinggi) dan hipotensi (tekanan darah rendah). Namun untuk frekuensi atau seringnya angka kekambuhan gejala pada pasien yang mengalami vertigo selalu tidak menentu, hal ini karena vertigo tersebut akan timbul jika pada pasien tersebut muncul faktor penyebabnya. Menurut Neurology Channel (2011), sistem vestibular tersebut bertanggung jawab untuk menghubungkan rangsangan terhadap indera dengan pergerakan tubuh dan menjaga agar suatu objek tetap berada dalam fokus ketika tubuh bergerak. Selain disebabkan oleh gangguan pada sistem vestibular dan gangguan pada otak, vertigo juga bisa disebabkan oleh faktor idiopatik, trauma, fisiologis, konsumsi obat dan penyakit atau sindrom lain seperti Meniere (Dewanto, 2009).

Menurut Wratsongko (2006), Vertigo biasa terjadi disertai dengan mual dan muntah, bahkan ada juga bisa disertai dengan diare. Akibat selanjutnya vertigo dapat menyebabkan dehidrasi dan jatuh. Banyak tindakan atau terapi yang sering digunakan oleh seseorang yang mengalami vertigo. Salah satunya yaitu terapi farmakologi atau obat. Seperti halnya upaya yang sudah dilakukan di praktik mandiri dokter yang akan diteliti yaitu memberikan obat untuk meringankan vertigo. Seseorang yang mengalami vertigo biasa mengkonsumsi obat untuk mengurangi atau menghilangkan gejala vertigo. Namun obat yang di konsumsi tentu saja memiliki efek samping. Banyak terapi-terapi lain selain farmakologi. Salah satunya terapi rehabilitasi vestibular yaitu Epley Manuver, Semount Manuver dan Brandt Daroff atau Brandt Daroff Exercise.

Salah satu bentuk terapi fisik non farmakologi yang dapat mengurangi atau menghilangkan gejala tersebut adalah dengan menggunakan metode Brandt Daroff yang merupakan bentuk terapi fisik atau senam fisik vestibuler untuk mengatasi gangguan vestibular seperti vertigo. Terapi fisik ini dilakukan untuk mengadaptasikan diri terhadap gangguan keseimbangan. Latihan Brandt Daroff memiliki keuntungan atau kelebihan dari terapi fisik lainnya atau dari terapi farmakologi yaitu dapat mempercepat sembuhnya vertigo dan untuk 
mencegah terjadinya kekambuhan tanpa harus mengkonsumsi obat. Selain itu, latihan Brandt Daroff dapat meningkatkan kualitas hidup pasien dan pasien tidak perlu berkeliling mencari dokter yang bisa menyembuhkan vertigonya. Namun, selain kelebihan-kelebihan diatas, metode ini juga memiliki kelemahan yaitu metode ini tidak boleh langsung dilakukan setelah pasien diberikan terapi epley manuver maupun semont manuver (Bahrudin, 2013; Lumbantobing, 2001). Dalam penelitian yang sudah dilakukan oleh Sumarliyah dkk (2011), senam vertigo dengan menggunakan metode Brandt Daroff dapat memaksimalkan kinerja tiga sistem yang berfungsi sebagai alat keseimbangan.

Penelitian ini bertujuan untuk mengetahui pengaruh pemberian terapi fisik Brandt Daroff terhadap vertigo di UGD RSUD Dr. R Soedarsono Pasuruan.

\section{METODE PENELITIAN}

Penelitian ini menggunakan jenis penelitian Quasi Eksperiment dengan menggunakan rancangan Pre-test and Post-test Group. Di dalam desain ini observasi dilakukan sebanyak 2 kali yaitu sebelum eksperimen dan sesudah eksperimen. Observasi yang dilakukan sebelum eksperimen disebut pre-test dan observasi sesudah eksperimen disebut post-test (Setiadi, 2013). Penelitian ini dilaksanakan di Ruang UGD RSUD Dr R Soedarsono kota Pasuruan pada tanggal 12 Juni sampai 8 Juli 2017.

Populasi adalah keseluruhan subjek penelitian (Suharsimi, 2010). Populasi dalam penelitian ini adalah pasien vertigodi RSUD Dr R Soedarsono kota Pasuruan. Sampel dalam penelitian ini diambil dengan menggunakan teknik pengambilan sampel Non Probability Sampling dengan jenis Consecutive Sampling dengan jumlah 30 sampel. Kriteria inklusi pasien vertigo adalah bersedia menjadi responden, mampu berkomunikasi baik, bersedia mengikuti dan menjalani terapi fisik selama penelitian berlangsung, kesadaran composmentis. Kriteria eksklusi pasien yang kurang kooperatif, mengalami keterbatasan gerak.

Data primer, data primer diambil langsung dari responden dengan cara pengunaan lembar observasi. Data sekunder, data sekunder terdiri dari gambaran umum lokasi penelitian dan data pasien yang mengalami vertigo. Instrument yang digunakan dalam penelitian ini adalah SOP Terapi fisik Brandt Daroff, Lembar vertigo symptom scale-short form (VSS-SF), Lembar observasi, Kuosioner responden. Teknik pengolahan data Editing, Coding, Entry, Cleaning. Tabulasi data ,entri data menggunakan analisa univariat, analisa bivariat. Data yang diperoleh daripenelitian dianalisis dengan uji Wilcoxon Sign Rank Test. Etika penelitian meliputi Benefience, Respect $\mathrm{Hu}$ man Dignity, Right to Justice.

Penelitian ini dilakukan dengan cara pemberian terapi fisik Brandt Daroff. Untuk terapi fisik Brandt Daroffdiberikan sebanyak 5-10 kali dalam waktu 1 hari di UGD RSUD Dr. R Soedarsono Kota Pasuruan. Setelah dilakukan 5-10 kali selama sehari pada kelompok terapi fisik Brandt Daroffdidapatkan penurunan skor vertigo pada pasien vertigo.

\section{HASIL PENELITIAN PEMBAHASAN}

Dari hasil penelitian ini menunjukkan bahwa vertigo yang dirasakan pasien dengan sebelum dilakukan terapi fisik Brandt Daroff sebagian besar mengalami vertigo sedang dengan jumlah 16 orang (54\%), sedangkan yang mengalami vertigo ringan dengan jumlah 13 orang (44\%), dan yang mengalami vertigo berat dengan jumlah 1 orang (2\%). Hal ini dapat dilihat bahwa sebagian besar yang mengalami vertigo adalah pasien dengan dewasa akhir usia $33 \mathrm{~s} / \mathrm{d} 40$ tahun. Serta kebanyakan pasien berjenis kelamin perempuan.

Dari hasil penelitian, dapat dilihat bahwa pasien paling banyak yang mengalami vertigo kategori sedang berjumlah 16 orang, hal ini dimungkinkan karena setiap individu mempunyai tingkat ambang vertigo yang berbeda-beda. Menurut Putranta (2005) seseorang yang menderita vertigo disebabkan oleh gangguan keseimbangan yang berpusat di area labirin atau rumah siput di daerah telinga. Perasaan tersebut kadang disertai dengan rasa mual dan ingin muntah, bahkan 
penderita merasa tidak mampu berdiri dan kadang terjatuh karena masalah keseimbangan. Keseimbangan tubuh dikendalikan oleh otak kecil yang mendapat informasi mengenai posisi tubuh dari organ keseimbangan di telinga tengah dan mata. Vertigo biasanya timbul akibat gangguan telinga tengah dan dalam atau gangguan penglihatan.

Opini tersebut dikuatkan dengan teori dari Iskandar (2011) vertigo merupakan perasaan seolah-olah penderita bergerak atau berputar, puyeng atau seolah-olah benda di sekitar penderita bergerak atau berputar. Vertigo biasanya disertai dengan mual dan kehilangan keseimbangan. Kejadian vertigo ini bisa hanya berlangsung beberapa saat atau bisa berlanjut sampai beberapa jam bahkan hari. Terkadang pasien juga dapat merespon vertigo yang dialaminya dengan cara berbaring diam supaya merasa lebih baik, tetapi vertigo bisa terus berlanjut meskipun penderita tidak bergerak sama sekali.Menurut Joesoef (2002) rasa pusing atau vertigo disebabkan oleh gangguan alat keseimbangan tubuh yang mengakibatkan ketidakcocokan antara posisi tubuh yang sebenarnya dengan apa yang dipersepsi oleh susunan saraf pusat.

Hasil penelitian menunjukkan bahwa vertigo yang dirasakan pasien dengan sesudah dilakukan terapi fisik Brandt Daroff sebagian besar mengalami vertigo ringan dengan jumlah 29 orang (98\%), sedangkan yang mengalami vertigo sedang dengan jumlah 1 orang $(2 \%)$. Hal ini didapatkan bahwa terapi fisik Brandt Daroff dapat mengurangi vertigo.

Pada penelitian ini peneliti berpendapat bahwa terapi fisik Brandt Daroff sangatmembantu untuk mengurangi munculnya vertigo. Hal ini dapat terbukti dari hasil penelitian diatas bahwa pada pasien yang mengalami vertigo sedang menurun menjadi vertigo ringan dengan jumlah 29 orang $(98 \%)$

Menurut Wreksoatmojo (2010) Adanya sensasi gerakan atau rasa gerak dari tubuh seperti rotasi (memutar) tanpa sensasi perputaran yang sebenarnya, dapat sekelilingnya terasa berputar atau badan yang berputar. Keluhan yang paling sering dijumpai dalam praktek. Vertigo berasal dari bahasa latin "vertere" yaitu memutar. Vertigo termasuk ke dalam gangguan keseimbangan yang dinyatakan sebagai pusing, pening, sempoyongan, rasa seperti melayang atau dunia seperti berjungkir balik. Vertigo paling sering ditemukan adalah $B e$ nign Paroxysmal Positional Vertigo (BPPV). Menurut penelitian pasien yang datang dengan keluhan pusing berputar atau vertigo, sebanyak $20 \%$ memiliki BPPV, walaupun penyakit ini sering sering disertai penyakit lainnya.

Opini tersebut dikuatkan dengan teori dari (Israr, 2008) juga berpendapat bahwa terdapat gejala-gejala yang mempengaruhi vertigo diantaranya mual, muntah, kehilangan keseimbangan, berkeringat berlebih, dan jantung berdebar. Menurut Wratsongko (2006) vertigo biasa terjadi disertai dengan mual dan muntah, bahkan ada juga bisa disertai dengan diare. Akibat selanjutnya vertigo dapat menyebabkan dehidrasi dan jatuh. Banyak tindakan atau terapi yang sering digunakan oleh seseorang yang mengalami vertigo. Salah satunya yaitu terapi farmakologi atau obat. Seseorang yang mengalami vertigo biasa mengkonsumsi obat untuk mengurangi atau menghilangkan gejala vertigo. Namun obat yang di konsumsi tentu saja memiliki efek samping. Banyak terapi-terapi lain selain farmakologi. Salah satu bentuk terapi fisik non farmakologi yang dapat mengurangi atau menghilangkan gejala vertigo adalah dengan menggunakan metode Brandt Daroff yang merupakan bentuk terapi fisik atau senam fisik vestibuler untuk mengatasi gangguan vestibuler seperti vertigo.

Wilhelmsen et al., (2008) Nilai total skor $>12$ menunjukkan seseorang menderita vertigo dan juga memiliki skala masing-masing. Diantaranya jika skor 12-20 (vertigo ringan), 21-30 (vertigo sedang), $>31$ (vertigo berat).

Hasil penelitian menunjukkan ada pengaruh terapi fisik Brandt Daroff terhadap vertigo dimana pada tindakan terapi fisik Brandt Daroff didapatkan penurunan skor vertigo sebelum dan sesudah dilakukan terapi fisik Brandt Daroff. Pada uji Wilcoxon didapatkan nilai Z -4,787 dengan nilai probabilitas $0,000(\mathrm{p}<0,05)$ yang berarti Ho ditolak dan $\mathrm{H} 1$ diterima artinya ada 
pengaruh sebelum dan sesudah dilakukan terapi fisik Brandt Daroff.

Dari hasil penelitian, peneliti berpendapat bahwa terapi fisik Brandt Daroff merupakan tindakan mandiri perawat yang mudah diterapkan dan efektif untuk mengurangi vertigo.Selain gerakannya mudah untuk dilakukan secara mandiri oleh pasien, terapi fisik Brandt Daroff juga sangat aman dilakukan walaupun tanpa pengawasan tenaga ahli. Terapi fisik Brandt Daroff merupakan teknik sederhana yang dapat dilakukan di rumah.

Joesoef (2006) \& Wreksoatmodjo (2004) Rasa pusing atau vertigo disebabkan oleh gangguan keseimbangan tubuh yang mengakibatkan ketidakcocokan antara posisi tubuh yang sebenarnya dengan apa yang dipersepsi oleh susunan saraf pusat. Salah satu bentuk terapi fisik non farmakologi yang dapat mengurangi atau menghilangkan gejala vertigo adalah dengan menggunakan metode Brandt Daroff. Menurut Bahrudin (2013) \& Lumbantobing (2001) terapi fisik ini dilakukan untuk mengadaptasikan diri terhadap gangguan keseimbangan. Latihan Brandt Daroff memiliki keuntungan atau kelebihan dari terapi fisik lainnya atau dari terapi farmakologi yaitu dapat mempercepat sembuhnya vertigo dan untuk mencegah terjadinya kekambuhan tanpa harus mengkonsumsi obat. Dalam penelitian yang sudah dilakukan oleh Sumarliyah dkk (2011), senam vertigo dengan menggunakan terapi fisik Brandt Daroff dapat memaksimalkan kinerja tiga sistem yang berfungsi sebagai alat keseimbangan. Menurut informasi dari Cambridge University Hospital (2014), Brandt Daroff memiliki kelebihan yaitu mengurangi respon stimuli yang berupa perasaan tidak nyaman dan sensasi berputar pada otak, dan juga membantu mereposisi Kristal yang berada pada kanalis semisirkularis.

Opini tersebut dikuatkan dengan teori dari Mamahit (2012), latihan Brandt Daroff berperan meningkatkan efek adaptasi dan habituasi sistem vestibular dan pengulangan yang lebih sering pada latihan Brandt Daroff berpengaruh dalam proses adaptasi pada tingkat integrasi sensorik. Integrasi sensorik juga bekerja dalam penataan kembali ketidakseimbangan input antara sistem organ vestibular dan persepsi sensorik lainnya. Tahapan gerakan latihan Brandt Daroff mendispersikan gumpalan otolit menjadi partikel yang kecil sehingga menurunkan keluhan vertigo. Hal tersebut dibuktikan dengan penelitian terdahulu yang dilakukan oleh Widjajalaksmi (2015), dimana didapatkan hasil penelitian $\mathrm{p}=0,000(\mathrm{p}<0,05)$. Maka dapat disimpulkan bahwa terapi fisik Brandt Daroff dapat menurunkan gejala vertigo pada vertigo.

Keterbatasan penelitian ini adalah untuk mengetahui keakuratan obat dan mengurangi vertigo peneliti maupun responden tidak mengetahui obat yang diberikan dan Feasibility yaitu dalam melakukan penelitian adanya pertimbangan mengenai keterbatasan waktu, dana, keahlian dan pertimbangan etik.

\section{PENUTUP}

Berdasarkan hasil analisa data yang diperoleh dari penelitian dapat disimpulkan bahwa sebelum dilakukan terapi fisik Brandt Daroff tingkat vertigo sebagian besar tingkat sedang sebanyak 16 orang. Sesudah dilakukan terapi fisik Brandt Darofftingkat vertigo sebagian besar tingkat ringan sebanyak 29 orang. Terdapat pengaruh terapi fisik Brandt Daroff terhadap vertigo di RSUD Dr. R Soedarsono Pasuruan dengan $p$ value $=0,000$.

Terapi fisik Brandt Daroffdalam memberikan tindakan perlu diawali dengan pemeriksaan yang teliti, penegakan diagnosa yang benar, pemberian edukasi yang benar dan mengevaluasi hasil terapi yang rutin agar memperoleh hasil terapi yang optimal dan terdokumentasi dengan baik.

Pengobatan pada kasus ini sebaiknya diberikan seawal mungkin dan perlu juga mengajarkan di rumah (Home program) kepada pasien seperti: saat tidur jangan menggunakan bantal yang terlalu tebal dan keras, tidak dibenarkan menggerakkan leher secara spontan, tidur dengan posisi yang benar yaitu terlentang dan olahraga yang teratur. Pada pasien agar selalu memperhatikan anjuran atau larangan tim medis 
yang kiranya mengganggu kesembuhan pasien dan untuk kesembuhan melaksanakan program terapi fisik Brandt Daroff secara intensif sesuai dengan petunjuk yang telah diberikan oleh terapis demi keberhasilan suatu terapi. Kepada keluarga pasien agar selalu memberikan dorongan atau support, serta membantu pasien untuk melaksanakan program terapi terutama di rumah.

\section{DAFTAR PUSTAKA}

Bisdorff A. (2013). The Epidemiology of Vertigo, Dizziness, and Unsteadiness and its links to co-mordibities. Frontiers in Neurology. Vol 4 article 2

Chaker Rahul T., Eklare, Nishikant. (2012). Vertigo in Cerebrovaskuler Disease. Otolaryngology Clinics : An International Journal. 4 (1): 46-53

Dewanto G., 2009. Diagnosis dan Tatalaksana Penyakit Saraf. Jakarta: Buku Kedokteran EGC

Grill E., Muller M., Brantdt M. (2013). Vertigo and Dizziness: challenges for epidemiological research. OA Epidemiology. 1(2): 12

Iskandar. (2011). Benign Paroxymal Positional Vertigo: Diagnosis and Treatment. International Tinnitus Journal.

Israr, Y. A. (2008). Vertigo Faculty of Medicine University of Riau. Available in: Http:/ /yayanakhyar.wordpress.com

Joesoef, AA, Kusumawati, K. 2002. Tinjauan Umum Mengenai Vertigo. Surabaya: Airlangga University Press

Lumbantobing, S.M. (2001). Vertigo. Jakarta: FKUI

Marchiori, L,L., Melo, J.J., P ossette, F.L., and Correa, A.L. (2010). Comparison of Frequency of Vertigo in Elderly with and with- out Arterial Hypertension, Intl. Arch. Otorhinolaryngol, 14 (4), 456-460.

Mamahit, Andy Ardhana. (2012). Pengaruh latihan Brandt Daroff dan Modifikasi Manuver Epley Pada Vertigo Posisi Paroksismal Jinak Tesis. Universitas Indonesia.

Mudzakir, N. (2009). Pendekatan Statistika Modern untuk Ilmu Sosial. Jakarta: Salemba Humanika.

Putranta. (2005). Panduan Praktis Diagnosis \& Tatalaksana Penyakit Saraf. Jakarta: EGC.

Rustinah, F., Brastho, B., Widayat, A., \& Jenny, B. (2008). Evaluasi Pasien Vertigo Posisi Paroksimal Jinak dengan Terapi Reposisi Kanalit dan Latihan Brandt Daroff. Fakultas Kedokteran Universitas Indonesia.

Sumarilyah, E., 2010. Jurnal Penelitian Pengaruh Senam Vertigo Terhadap Keseimbangan Tubuh pada Pasien Vertigo di RS Siti Khodijah Sepanjang. RS Siti Khodijah Sepanjang: Jawa Timur.

Widjajalaksmi, K. (2015). Pengaruh Latihan Brandt Daroff Dan Modifikasi Manuver Epley Pada Vertigo Posisi Paroksimal Jinak. Jakarta.

Wilhelmsen K. et al. (2008). Psychometric Properties of the Vertigo Symptom Scale-Short Form. BMC Ear, Nose, and Throat Disorders. $8: 2$

Wratsongko, M. (2006). Pedoman Sehat Tanpa Obat. Jakarta: PT. Elex Media Komputindo

Wreksoatmodjo, B, R. (2004). Vertigo: Aspek Neurologi. Bogor: Cermin Dunia Kedokteran 